\title{
Dynamics and Control of Liquid Level in Annular Conical Tank Process: Modelling and Experimental Validation
}

\author{
Anupam Srivastav, Parmanand Maurya, R. S. Singh and Durga Prasad* \\ Department of Chemical Engineering and Technology, Indian Institute of Technology \\ (Banaras Hindu University) Varanasi - 221005, Uttar Pradesh, India; \\ anupamsrivastav.che17@itbhu.ac.in, parmanandm.che17@itbhu.ac.in, \\ rssingh.che@itbhu.ac.in,dprasad.che@itbhu.ac.in
}

\begin{abstract}
Objectives: The present work has been carried out to prove the superiority of IMC based PID control strategy over the conventional PID, based on simulation studies and experimental validation on an annular conical tank liquid level nonlinear process. Methods/Statistical Analysis: First principles based Mathematical Model of an annular conical tank liquid level nonlinear process has been developed based on the mass balances and outlet flow hydraulic characteristics. Linearization of the nonlinear model at a specific steady-state operating point led to the theoretical development of state-space and standard first order transfer function models. Open loop and closed loop experimental studies on a computer controlled physical setup were performed to identify the parameters of a FOPDT Model with variable gain and time constant. IMC based PID controller was designed and compared to the conventional PID controller. Findings: The variation in process parameters was attributed to two factors: (a) the variation in annular cross sectional area of the conical tank at different levels, and (b) the variation in outlet flow resistance. The IMC based PID controller has been shown to exhibit superior performance in terms of quantitative performance indices such as ISE, IAE, ITAE, rise time, settling time and percentage overshoot, at four different steady-states. Application/Improvements: Study of Modelling of annular conical tank process and a systematic methodology of process system identification from experimental setup have been reported. The advantages of IMC based PID controller design over the conventional PID tuning method has been experimentally verified.
\end{abstract}

Keywords: Annular Flow Conical tank process, FOPDT model, System Identification, PID controller tuning, IMC based PID.

\section{Introduction}

Conical tanks are extensively used in the various process industries as its shape provides better drainage of solid mixtures, slurries and viscous liquids. The process nonlinearity in conical tanks is caused by two factors: (a) its constantly varying cross-section and (b) the nonlinear flow resistance. Various works have been published in literature that address the conical tank level control methodologies based on simulation results of selected process models. While the simulation results may offer satisfactory control, thereare deviations when implemented on practical experimental setups. This may be attributed to the dynamics associated with the various components of the setup and also the process noise associated with the instrumentation. The present work addresses both the simulation studies as well as experimental validation on laboratory scale physical setup.

Many researchers have published works on the level control of conical tank processes. In 1 proposed the PID Controller tuning method for open and closed loop systems and it was utilized for the level control of conical tank. In² proposed the auto tuning method for the (PID) Controller, using dominant pole design technique. $\operatorname{In}^{3}$

*Author for correspondence 
Proposed Closed-loop automatic tuning of PID controller for nonlinear systems. $\operatorname{In}^{4}$ proposed presents the synthesis and analysis of optimal tuning of (PID) controller tuning parameters for (FOPTD), (SOPTD) systems.

Apart from using simple PID to various modified PID many model predictive control and fuzzy control technique have been studied and published. In ${ }^{5}$ proposed Introduced Design Procedure and Simulation result of Internal Model Controller for a Real Time Nonlinear Process. In ${ }^{6}$ proposed Model based Controller Design for nonlinear Conical Tank System. In ${ }^{7}$ proposed Introduced Optimal Actuation of PI Controller using Predictive Technique for Level Control of Nonlinear Process. $\operatorname{In}^{8}$ proposed Introduced design procedure of Internal Model Controller to establish PID rules with a well described approach. In-9 proposed Developed nonlinear inferential control (NLIC as a method for improving control of nonlinear systems. In ${ }^{10}$ Proposed Model reference Adaptive Control based on neural network for level control of non-linear process. In 11 developed design of a soft computing based controller for level control of non linear conical tank process. In $\underline{12}$ Proposed Online tuning of fuzzy logic controller using Kalman algorithm. In ${ }^{13}$ Devloped the technique for level control of conical tanksystem using fuzzy based model predictive controller (FMPC). In ${ }^{14}$ Developed a Smart controller for level control of non linear conical tank system using reinforcement learning algorithm and eliminated the drawbacks of PID and fuzzy controllers. In ${ }^{15}$ Proposed level control of non linear conical tank using PID controller and fuzzy logic algorithm. In ${ }^{16}$ PG Presented a comparative study of PI controller, model reference adaptive controller and fuzzy logic controller for a coupled tank system.

In ${ }^{17}$ developed Takagi-Sugeno fuzzy model for direct inverse control of conical tank system. In the present work, the conventional PID controller and IMC based PID Controller $\frac{18-20}{}$ has been implemented on a non linear annular flow conical tank process. Our work is primarily divided into two sections: (a) Experimental and (b) Modeling. Various sections of our work include process description, Mathematical Modelling of annular flow conical tank process, System Identification andstudy of steady-state and dynamic behaviour of the process (based on experimental runs), Controller design techniques 21 and closed loop responses with experimental validation.

\section{Nonlinear Conical Tank Liquid Level Process}

The experimental setup designed by Apex Innovations ${ }^{22}$ is shown in Figure 1 and the technical specification of setup has been shown in Table 1. The control objective is to maintain the liquid level (as measured by a Level Transmitter) at desired steady-state by manipulating the inlet flowrate to the tank. The setup is interfaced to a computer which records all the desired process variables

Table 1. Specification of setup

\begin{tabular}{|r|l|}
\hline Product & Non Linear Level control trainer \\
\hline Type of control & Direct Digital Control \\
\hline I/P converter & Input 4-20mA, Output 3-15 psig. \\
\hline Control valve & $\begin{array}{l}\text { Pneumatic type, Linear Characteristic, } \\
\text { Direct Acting, Size 1/4", Input 3-15 psig. }\end{array}$ \\
\hline Rotameter & 10-100 LPH, Make: Eureka \\
\hline Pump & $\begin{array}{l}\text { Submersible type having fractional horse } \\
\text { power. }\end{array}$ \\
\hline Process tank & $\begin{array}{l}\text { Acrylic cylindrical with cylindrical to } \\
\text { linear conical conversion with 0-100\% } \\
\text { graduated scale. }\end{array}$ \\
\hline
\end{tabular}

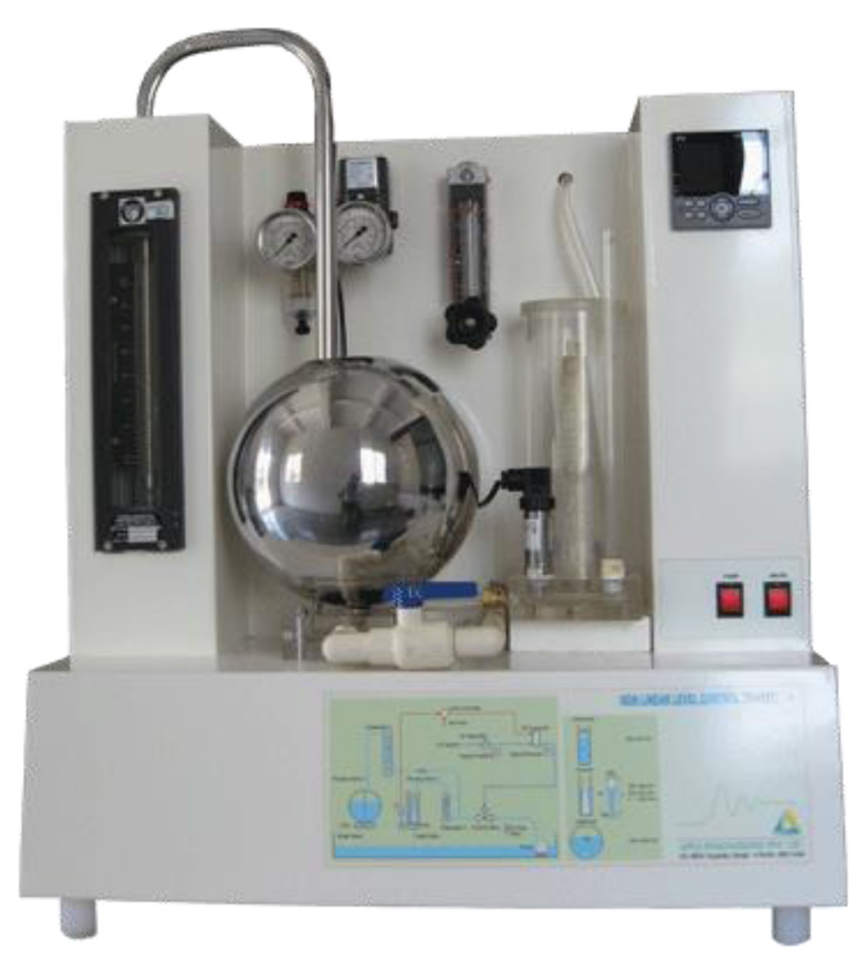

Figure 1. Experimental setup of conical tank liquid level process. 


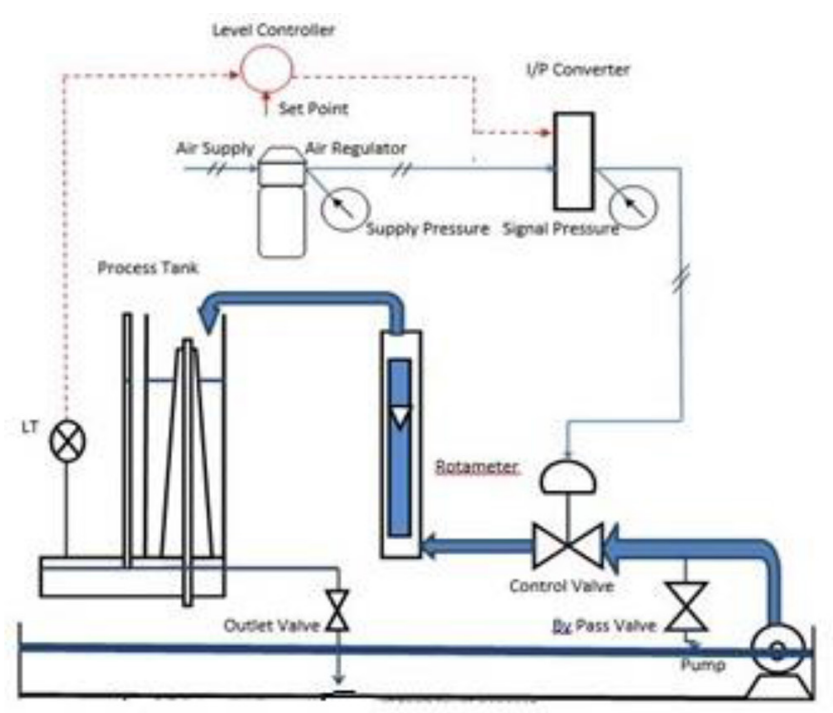

Figure 2. Schematic diagram of conical tank liquid level process.

and implements the Direct Digital Control action on the process. The setup consists of a reservoir tank, submersible pump, pneumatic control valve (linear, air to close), I to $\mathrm{P}$ converter, annular conical tank and level sensor. The schematic process diagram of the setup is shown below in Figure 2. The setup can be operated in two modes:

(a) Auto Mode: To control the liquid level in closed loop using a PID Controller

(b) Manual Mode: To study the open loop dynamics by manually changing the Controller Output (OP \%) signal which in turn provides step change in the input flowrate to the process through the final control element (control valve).

\section{Mathematical Modelling of Annular Flow Conical Tank Process}

\subsection{Process Variables and Parameters}

Consider the annular flow conical tank process model as shown in Figure 3.

The input-output variables and parameters associated with the process model (along with their operating values) are shown as under:

$\mathrm{H}=$ Height of cylindrical tank $=290 \mathrm{~mm}$

$\mathrm{D}=$ Diameter of the cylindrical tank $=92 \mathrm{~mm}$

$\mathrm{F}_{\mathrm{i}}=$ Volumetric flow rate of inlet stream $(\mathrm{LPH})$

$\mathrm{F}_{\mathrm{o}}=$ Volumetric flow rate of the outlet stream (LPH)

$\mathrm{h}_{\max }=$ Height of cone $\mathrm{h}_{1}=255 \mathrm{~mm}$

$\mathrm{h}_{2}=245 \mathrm{~mm}$

$\mathrm{d}_{1}=$ Bottom Diameter of cone $=88 \mathrm{~mm}$

$\mathrm{d}_{2}=$ Top Diameter of cone $=25 \mathrm{~mm}$

$\beta=$ Outlet flow (nonlinear) resistance $=6.03674 \mathrm{LPH} /$ $\mathrm{cm}^{\wedge} 0.5$

\subsection{Model Equations}

Consider the differential volume of cone at any height:

$$
d V_{C}=\frac{\pi d^{2}}{4} d h \ldots
$$

Assume linear variation of diameter with respect to the height of cone

$$
d(h)=a_{1} h+a_{2} \ldots
$$

Evaluate $\mathrm{a}_{1} \& \mathrm{a}_{2}$ using the Boundary Conditions:

$$
\begin{gathered}
\text { BC1: at } \mathrm{h}=0, \mathrm{~d}=\mathrm{d}_{1} \text { gives } a_{2}=\mathrm{d}_{1} \ldots \\
\text { BC2 }: \text { at } \mathrm{h}=\mathrm{h} 2, \mathrm{~d}=\mathrm{d}_{2} \text { gives } a_{1}=\frac{d_{2}-d_{1}}{h_{2}} \ldots
\end{gathered}
$$

The maximum height $\mathrm{h}_{\max }$ can be evaluated using Equation (2) when $d=0$

$$
h_{\max }=\frac{d_{1} h_{2}}{d_{1}-d_{2}} \ldots
$$

Total volume of cone can be obtained by integrating equation (1)

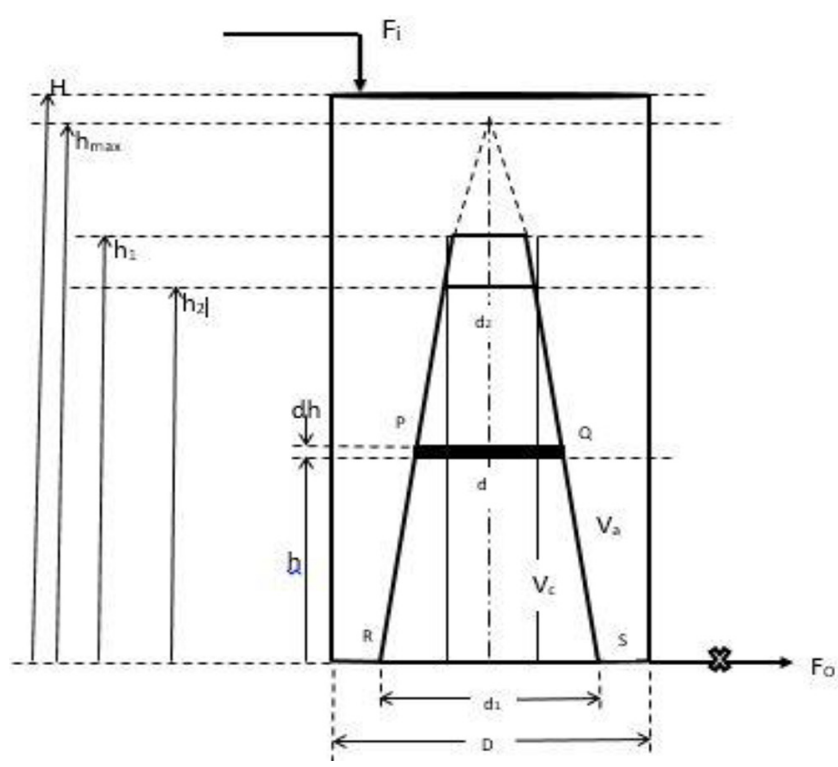

Figure 3. Annular flow conical tank process model. 


$$
\begin{gathered}
\int d V_{c}=\int \pi\left(a_{1} h+a_{2}\right)^{2} d h \ldots \\
V_{c}=\frac{\pi\left(a_{1} h+a_{2}\right)^{3}}{12 a_{1}}+C_{1} \ldots
\end{gathered}
$$

Evaluate $\mathrm{C}_{1}$ using $\mathrm{BC}$

$$
\mathrm{BC} 3: \mathrm{h}=0, V_{C}=0
$$

$$
\begin{gathered}
C_{1}=\frac{\pi a_{2}^{3}}{12 a_{1}} \ldots \\
V_{c}=\frac{\pi\left(a_{1} h+a_{2}\right)^{3}-\pi a_{2}^{3}}{12 a_{1}} \ldots
\end{gathered}
$$

Volume of annulus $=V_{a}$

Volume of $\operatorname{tank}=V_{T}$

$$
\begin{gathered}
V_{a}=V_{T}-V_{c} \ldots \\
V_{T}=\frac{\pi D^{2} h}{4} \ldots \\
V_{a}(h)=\frac{\pi D^{2} h}{4}-\frac{\pi\left(a_{1} h+a_{2}\right)^{3}-\pi a_{2}^{3}}{12 a_{1}} \ldots
\end{gathered}
$$

Mass balance around the annulus:

$$
F_{i} \rho-F_{o} \rho=\frac{d\left(V_{a} \rho\right)}{d t} \ldots
$$

Assuming constant density of fluid,

$$
\begin{gathered}
\frac{d V_{a}}{d t}=F_{i}-F_{o} \ldots \\
\text { Assume } F_{0}=\phi(h)=\beta \sqrt{h} \ldots \\
\frac{d V_{a}}{d t}=F_{i}-\beta \sqrt{h} \ldots \\
\frac{d V_{a}}{d t}=\frac{d V_{a}}{d h} \frac{d h}{d t} \ldots
\end{gathered}
$$

Replacing $V_{a}$ From Equation (10),

$$
\begin{gathered}
\frac{d V_{a}}{d t}=\frac{d\left(V_{T}-V_{c}\right)}{d h} \cdot \frac{d h}{d t} \\
\frac{d V_{a}}{d t}=\frac{d V_{T}}{d h} \frac{d h}{d t}-\frac{d V_{c}}{d h} \frac{d h}{d t} \cdots
\end{gathered}
$$

Since $\frac{d V_{T}}{d h}=\frac{\pi D^{2}}{4}$ (From Equation 11)

From equation (1) \& (2),

$$
\frac{d V_{c}}{d h}=\frac{\pi\left(a_{1} h+a_{2}\right)^{2}}{4} \ldots
$$

Substitute into (17)

$$
\frac{d V_{a}}{d t}=\left(\frac{\pi D^{2}}{4}-\frac{\pi\left(a_{1} h+a_{2}\right)^{2}}{4}\right) \frac{d h}{d t} \ldots
$$

Substitute equation (19) into the mass balance equation (15),

$$
\begin{gathered}
F_{i}-\beta \sqrt{h}=\left(\frac{\pi D^{2}}{4}-\frac{\pi\left(a_{1} h+a_{2}\right)^{2}}{4}\right) \frac{d h}{d t} \\
f\left(h, F_{i}\right)=\frac{d h}{d t}=\frac{F_{i}-\phi(h)}{\eta(h)} \ldots
\end{gathered}
$$

where,

$$
\eta(h)=\left(\frac{\pi D^{2}}{4}-\frac{\pi\left(a_{1} h+a_{2}\right)^{2}}{4}\right)=\frac{\pi}{4}\left(D^{2}-d^{2}\right) \ldots
$$

Equation (20) is the nonlinear differential equation that can be solved for steady-state as well as used for obtaining the dynamic response. From a control perspective, in terms of input-output model, the system can be viewed as a SISO system. The State space model of the system can be represented as:

$$
\begin{gathered}
\dot{x}=A x+B u \ldots \\
x=\left[h-h_{s}\right] \\
u=\left[F_{i}-F_{i s}\right]
\end{gathered}
$$

Here the steady state condition is denotes by subscripts s.

$$
\begin{gathered}
f\left(h_{s}-F_{i s}\right)=\frac{d h_{s}}{d t}=\frac{F_{i s}-\phi\left(h_{s}\right)}{\eta\left(h_{s}\right)}=0 \ldots \\
\phi\left(h_{s}\right)=\beta \sqrt{h_{s}}=F_{i s} \\
h_{s}=\left(\frac{F_{i s}}{\beta}\right)^{2} \ldots
\end{gathered}
$$




$$
\eta\left(h_{s}\right)=\left(\frac{\pi D^{2}}{4}-\frac{\pi\left(a_{1} h_{s}+a_{2}\right)^{2}}{4}\right) \ldots
$$

The elements of A and B Matrices of state space model can be obtained by linearization of nonlinear model (based on Taylor Series approximation at desired steady state operating point)

$$
A=\left.\frac{\partial f}{\partial x}\right|_{s}=\left.\frac{\partial f}{\partial h}\right|_{s} \ldots
$$

From equation (20)

$$
A=\left.\frac{\partial f}{\partial h}\right|_{s}=\left.\frac{\partial}{\partial h}\left(\frac{F_{i}}{\eta(h)}\right)\right|_{s}-\left.\frac{\partial}{\partial h}\left(\frac{\phi(h)}{\eta(h)}\right)\right|_{s} \ldots
$$

Evaluating the individual terms separately:

$$
\left.\frac{\partial}{\partial h}\left(\frac{F_{i}}{\eta(h)}\right)\right|_{s}=-\left.\frac{F_{i s}}{\eta^{2}\left(h_{s}\right)} \frac{\partial \eta(h)}{\partial h}\right|_{s} \ldots
$$

From Equation (21),

$$
\begin{gathered}
\frac{d \eta(h)}{d h}=-\frac{d}{d h}\left(\frac{\pi\left(a_{1} h+a_{2}\right)^{2}}{4}\right)+\frac{d}{d h}\left(\frac{\pi D^{2}}{4}\right) \\
\left.\frac{\partial \eta(h)}{\partial h}\right|_{s}=\frac{-\pi a_{1}\left(a_{1} h_{s}+a_{2}\right)}{2} \ldots
\end{gathered}
$$

Evaluating value of $\left(a_{1} h_{s}+a_{2}\right)$ From Equation (25),

$$
\begin{gathered}
a_{1} h_{s}+a_{2}=\frac{2}{\sqrt{\pi}} \times \sqrt{\left(\frac{\pi D^{2}}{4}-\eta\left(h_{s}\right)\right)} \ldots \\
\text { Now value of }\left.\frac{\partial \eta(h)}{\partial h}\right|_{s} \text { reduced to, } \\
\left.\frac{\partial \eta(h)}{\partial h}\right|_{s}=-\sqrt{\pi} \times a_{1} \times \sqrt{\left(\frac{\pi D^{2}}{4}-\eta\left(h_{s}\right)\right) \ldots} \\
\text { Using Equation (29B) Equation (28) reduced to, } \\
\left.\frac{\partial}{\partial h} \frac{F_{i s}}{\eta(h)}\right|_{s}=\frac{F_{i s} \times a_{1} \times \sqrt{\pi} \times \sqrt{\left(\frac{\pi D^{2}}{4}-\eta\left(h_{s}\right)\right)}}{\eta^{2}\left(h_{s}\right)} \ldots
\end{gathered}
$$

Now, evaluated the second term of (27),

$$
\left.\frac{\partial}{\partial h} \frac{\phi(h)}{\eta(h)}\right|_{s}=-\left.\frac{\phi\left(h_{s}\right)}{\eta^{2}\left(h_{s}\right)} \cdot \frac{\partial \eta(h)}{\partial h}\right|_{s}+\left.\frac{1}{\eta\left(h_{s}\right)} \frac{\partial \phi(h)}{\partial h}\right|_{s} \ldots
$$

$$
\left.\frac{d \phi(h)}{d h}\right|_{s}=\left.\frac{d(\beta \sqrt{h})}{d h}\right|_{s}=\frac{\beta}{2 \sqrt{h_{s}}} \ldots
$$

Substituted Equations (29 B) \& (32) into Equation (31),

$$
\begin{aligned}
&\left.\frac{\partial}{\partial h} \frac{\phi(h)}{\eta(h)}\right|_{s}= \frac{\phi\left(h_{s}\right) \times a_{1} \times \sqrt{\pi} \times \sqrt{\left(\frac{\pi D^{2}}{4}-\eta\left(h_{s}\right)\right)}}{\eta^{2}\left(h_{s}\right)} \\
&+\frac{1}{\eta\left(h_{s}\right)} \times \frac{\beta}{2 \sqrt{h_{s}}} \ldots
\end{aligned}
$$

Finally, substituted Equations (30) \& (33) into Equation (27),

$$
A=\left.\frac{\partial f}{\partial h}\right|_{s}=-\frac{1}{\eta\left(h_{s}\right)} \times \frac{\beta}{2 \sqrt{h_{s}}} \ldots
$$

Elements of B matrix,

$$
B=\left.\frac{\partial f}{\partial u}\right|_{s}=\left.\frac{\partial f}{\partial F_{i}}\right|_{s} \ldots
$$

From Equation (20),

$$
B=\frac{1}{\eta\left(h_{s}\right)} \ldots
$$

For SISO system,

$$
G_{p}(s)=\frac{B}{s-A}=\frac{x(s)}{u(s)} \ldots
$$

In gain- time constant form,

$$
G_{p}(s)=\frac{k_{p}}{\tau_{p} s+1} \ldots
$$

where, (37) can be re-written as,

$$
G_{p}(s)=\frac{B}{-A\left(-\frac{s}{A}+1\right)} \ldots
$$

where, the process gain and time constant are defined respectively as:

$$
k_{p}\left(h_{s}\right)=-\frac{B}{A}=\frac{2 \sqrt{h_{s}}}{\beta} \ldots
$$

$$
\tau_{p}\left(h_{s}\right)=-\frac{1}{A}=\eta\left(h_{s}\right) \frac{2 \sqrt{h_{s}}}{\beta} \ldots
$$


The process has a variable gain and variable time constant and since the Eigen value of $A$ matrix (as described by Equation 34) is negative, the system is stable. Equation (38) suggests that the conical tank system is first order system, characterized by its Capacitance and Resistance defined as $\eta\left(h_{s}\right)$ and $\frac{2 \sqrt{h_{s}}}{\beta}$ respectively.

\section{System Identification}

To begin with, the experimental setup was operated in Manual Mode. The parameters of process transfer function have been identified from experimental results of open loop responses. Since the controller output signal (measured as percentage of the maximum value) happens to be the input signal to the final control element (Pneumatic valve), the linear range of operation of the control valve was obtained in the controller output range of $42 \%$ to $80 \%$. The correlation between controller output and liquid inlet flowrate is obtained from the experimental data as shown in Figure 4 as:

$$
F=153.97-1.40(O P \%) \ldots
$$

An analogous correlation of liquid inlet flowrate with the Pneumatic valve stem pressure (input) has been obtained and shown in Figure 5 as:

$$
F=198.73-11.927 \times p \ldots
$$

The correlation between the Pneumatic valve stem pressure and the controller output is obtained and shown in Figure 6 as:

$$
p=3.89+.11 \times(O P \%) \ldots
$$

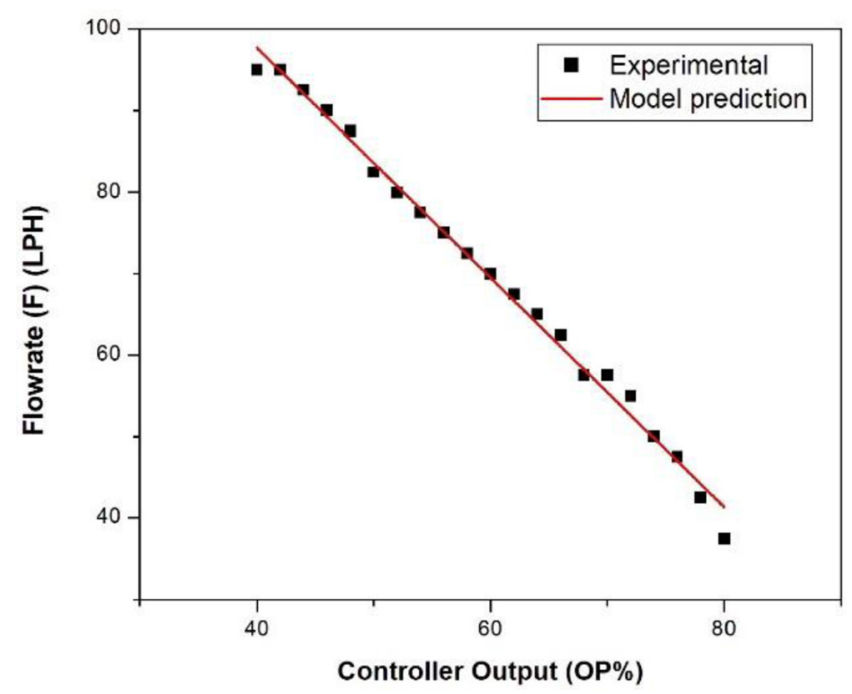

Figure 4. Relationship between flow rate and OP\%.

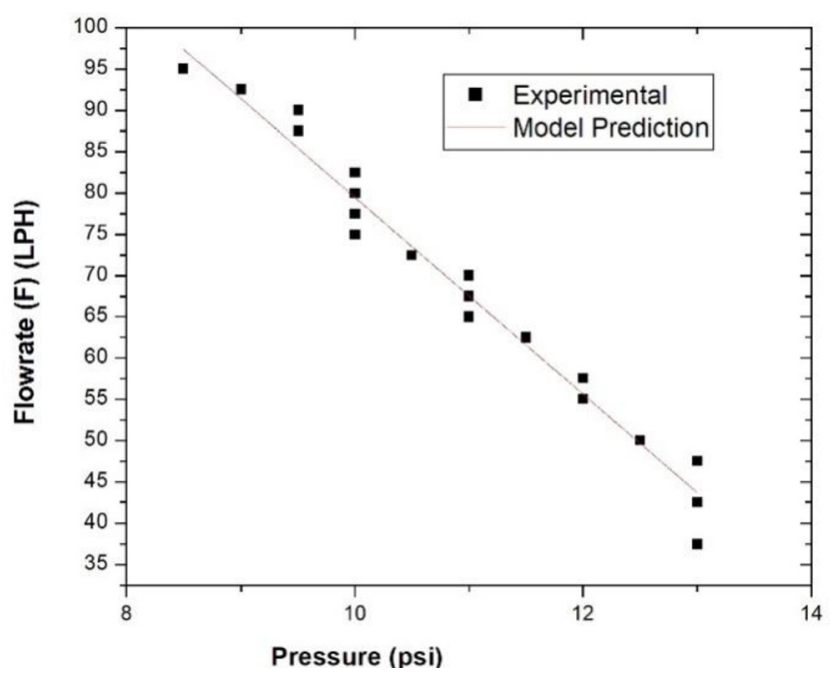

Figure 5. Relationship between flow rate and pressure.

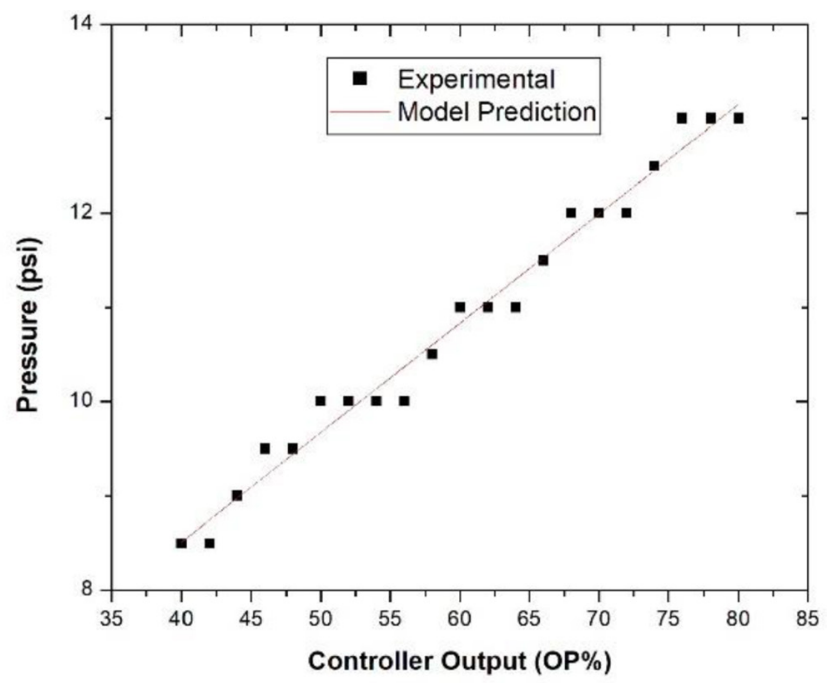

Figure 6. Relationship between pressure and OP\%.

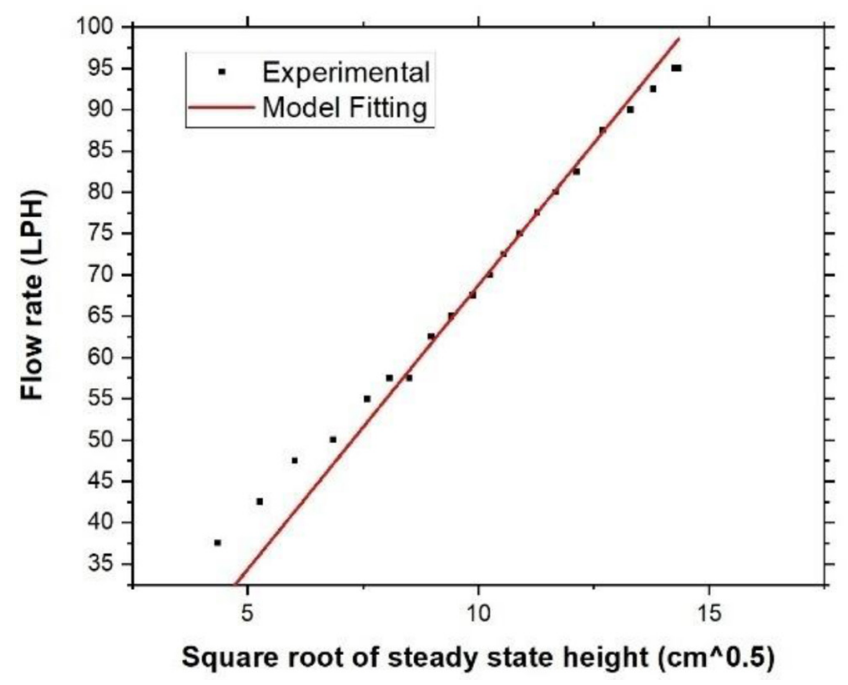

Figure 7. Estimation of outlet resistance (Beta)s. 
The outlet flow (nonlinear) resistance as defined in Equation $14 \mathrm{~A}$ has been obtained from the open loop experiments at various steady-state operating points, as shown in Figure 7. The value of beta estimated is 6.03674 $\mathrm{LPH} / \mathrm{cm}^{\wedge} 0.5$.

Based on Equation 41, the inlet liquid flowrates corresponding to the controller output range of $42 \%$ to $80 \%$ have been calculated to be in the range of $95.17 \mathrm{LPH}$ to $41.97 \mathrm{LPH}$.

\section{Steady-state and Dynamic Open Loop Responses}

The physical setup was operated at various steady-state operating points by changing the controller output in the range of $42 \%$ to $80 \%$. The corresponding steady-state flowrates were calculated and the steady-state heights were measured.

In order to obtain the transient open loop responses, the process was subjected to a small step change in the inlet flowrate by manually varying the controller output from $42 \%$ to $44 \%, 44 \%$ to $46 \%$ and so on. The transient responses between a pair of initial and final steady-states were used for the identification of Process parameters (time constant and steady-state gain) corresponding to various steady states, as shown in Table 2, using the following methods:

(a) Although the process is inherently first order, but experimental results revealed that there is a delay of approximately 5 seconds in the process output. This may be attributed to the dynamics associated with the other components in the setup. Using experimental data, the time constant is calculated by initial slope method and ultimate gain is obtained by the final value theorem based on the equation for a standard first order response:

$$
y(t)=\Delta u k_{p}\left[1-\exp \left(-\frac{t}{\tau_{p}}\right)\right] \ldots
$$

(b) A First Order plusDead time (FOPDT) model was therefore fitted to the experimental data using the

Table 2. Identification of Process parameters corresponding to various steady states

\begin{tabular}{|c|c|c|c|c|c|c|c|c|}
\hline \multirow{2}{*}{$\begin{array}{l}\text { Step } \\
\text { change in } \\
\text { Controller } \\
\text { output }\end{array}$} & \multirow{2}{*}{$\begin{array}{l}\text { Inlet liquid } \\
\text { Flow Rate } \\
(\mathrm{LPH}) \\
(\text { Eqn } 41)\end{array}$} & \multirow{2}{*}{$\begin{array}{l}\text { Steady State } \\
\text { Height } \\
\text { (Initial-Final) } \\
(\mathrm{Cm})\end{array}$} & \multicolumn{3}{|c|}{ Time Constant $\tau_{p}(\mathrm{Sec})$} & \multicolumn{3}{|c|}{ Steady State Gain $k_{p}(\mathrm{Cm} / \mathrm{LPH})$} \\
\hline & & & $\begin{array}{l}\text { Using } \\
\text { Experimental } \\
\text { Data (Eqn 44) }\end{array}$ & $\begin{array}{l}\text { Using } \\
\text { Nonlinear } \\
\text { Regression }\end{array}$ & $\begin{array}{l}\text { Using } \\
\text { Model } \\
\text { Prediction }\end{array}$ & $\begin{array}{l}\text { Using } \\
\text { Experimental } \\
\text { Data (Eqn 44) }\end{array}$ & $\begin{array}{l}\text { Using } \\
\text { Nonlinear } \\
\text { Regression }\end{array}$ & $\begin{array}{l}\text { Using } \\
\text { Model } \\
\text { Prediction }\end{array}$ \\
\hline $42-44 \%$ & 95.17-92.37 & $21.94-20.59$ & 41 & 64.27 & 85.42 & 0.48 & 0.59 & 1.50 \\
\hline $44-46 \%$ & $92.37-89.57$ & $20.59-19.17$ & 49 & 54.1 & 79.36 & 0.5 & 0.51 & 1.45 \\
\hline $46-48 \%$ & $89.57-86.77$ & $19.17-17.44$ & 13 & 16.27 & 71.77 & 0.6 & 0.53 & 1.38 \\
\hline $48-50 \%$ & $86.77-83.97$ & $17.44-15.96$ & 35 & 42.4 & 65.10 & 0.52 & 0.55 & 1.32 \\
\hline $50-52 \%$ & $83.97-81.17$ & $15.96-14.72$ & 27 & 42.63 & 59.36 & 0.43 & 0.45 & 1.27 \\
\hline $52-54 \%$ & $81.17-78.37$ & $14.72-13.74$ & 34 & 44.37 & 54.92 & 0.34 & 0.34 & 1.22 \\
\hline $54-56 \%$ & $78.37-75.57$ & $13.74-12.82$ & 38 & 42.5 & 50.68 & 0.31 & 0.32 & 1.18 \\
\hline $56-58 \%$ & $75.57-72.77$ & $12.82-12.05$ & 20 & 22.87 & 47.11 & 0.28 & 0.27 & 1.15 \\
\hline $58-60 \%$ & $72.77-69.97$ & $12.05-11.36$ & 22 & 23.29 & 43.94 & 0.23 & 0.25 & 1.11 \\
\hline $60-62 \%$ & $69.97-67.17$ & $11.36-10.62$ & 18 & 23.93 & 40.55 & 0.24 & 0.25 & 1.08 \\
\hline $62-64 \%$ & $67.17-64.37$ & $10.62-9.53$ & 23 & 27.74 & 35.61 & 0.36 & 0.33 & 1.02 \\
\hline $64-66 \%$ & 64.37-61.57 & $9.53-8.71$ & 15 & 22.94 & 31.93 & 0.29 & 0.29 & 0.97 \\
\hline $66-68 \%$ & 61.57-58.77 & $8.71-7.85$ & 15 & 17.17 & 28.18 & 0.27 & 0.24 & 0.92 \\
\hline $68-70 \%$ & $58.77-55.97$ & $7.85-7.01$ & 8 & 12.49 & 24.57 & 0.25 & 0.24 & 0.87 \\
\hline $70-72 \%$ & $55.97-53.17$ & $7.01-6.15$ & 17 & 23.48 & 20.97 & 0.29 & 0.25 & 0.82 \\
\hline $72-74 \%$ & $53.17-50.37$ & 6.15-5.05 & 11 & 11.96 & 16.61 & 0.38 & 0.37 & 0.74 \\
\hline $74-76 \%$ & $50.37-47.57$ & $5.05-3.97$ & 9 & 12.3 & 12.51 & 0.39 & 0.31 & 0.66 \\
\hline $76-78 \%$ & $47.57-44.77$ & $3.97-2.99$ & 8 & 8.56 & 9.04 & 0.36 & 0.25 & 0.57 \\
\hline $78-80 \%$ & $44.77-41.97$ & $2.99-2.02$ & 4 & 9.192 & 5.95 & 0.33 & 0.17 & 0.47 \\
\hline
\end{tabular}


nonlinear regression method. The fitted FOPDT Model has been compared with experimental data, as shown in Figure 8.

(c) Model prediction based on the Mathematical Model (Equations 39 and 40)

The nonlinear behaviour of the process can be examined from the variation of process gain and time constant at different steady-state operating points, as shown in Table 2. In addition, the process parameters computed by the Mathematical Model (Equations 39 and 40) show significant variation from the other methods. This may be attributed to the fact that the outlet resistance (Beta) calculated by Equation (14A) and Figure 7 may also be varying in real sense.
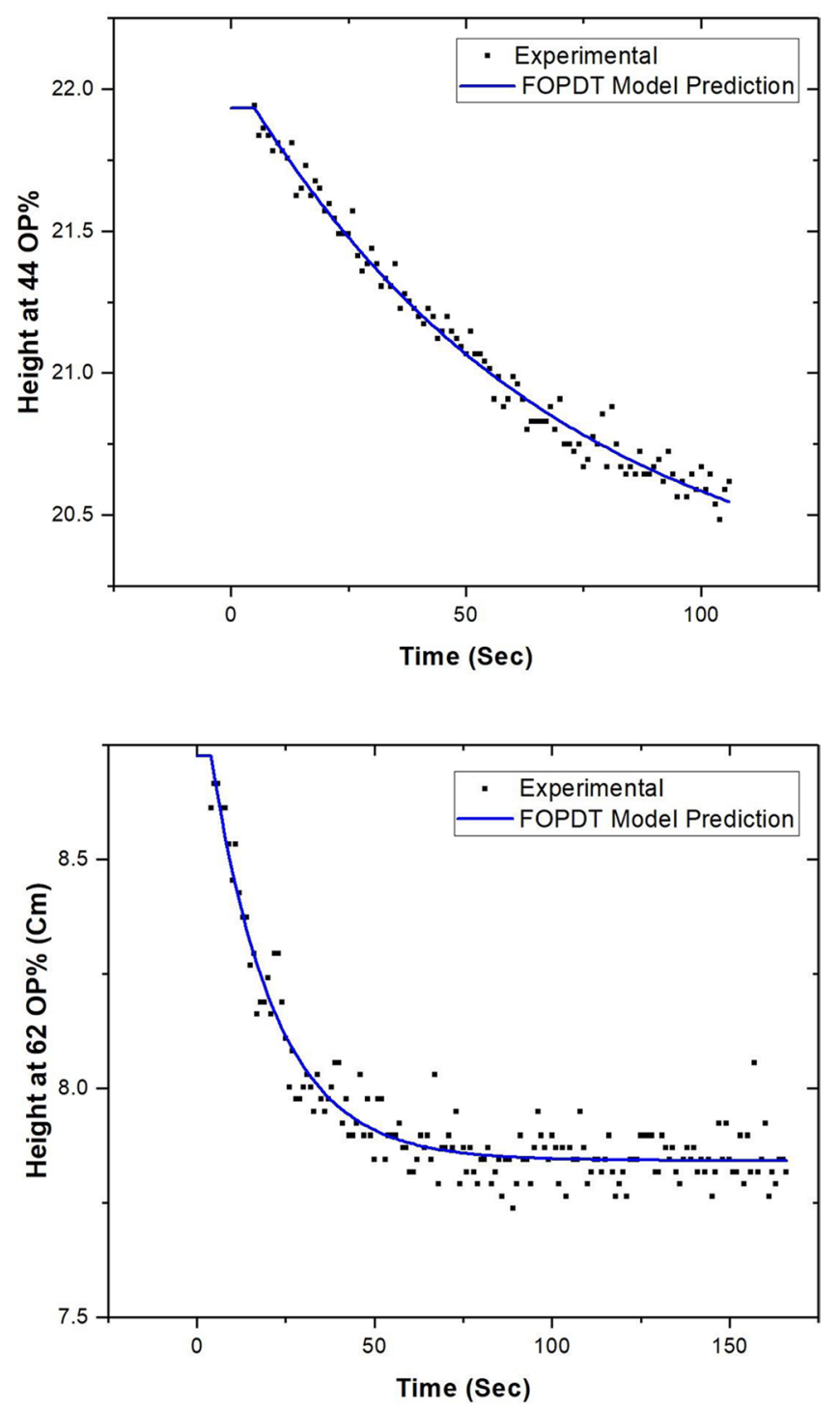

The variation in process time constant and gain with respect to the steady-state heights (as computed by the above three methods) has been shown in Figures 9 and 10 respectively.

\section{Controller Design}

\subsection{Controller Tuning based on Cohen and Coon Settings}

The open loop experimental process reaction curve (data as obtained by operating the setup in Manual Mode) was used to tune the conventional PID controller based on Cohen and Coon settings as described below:
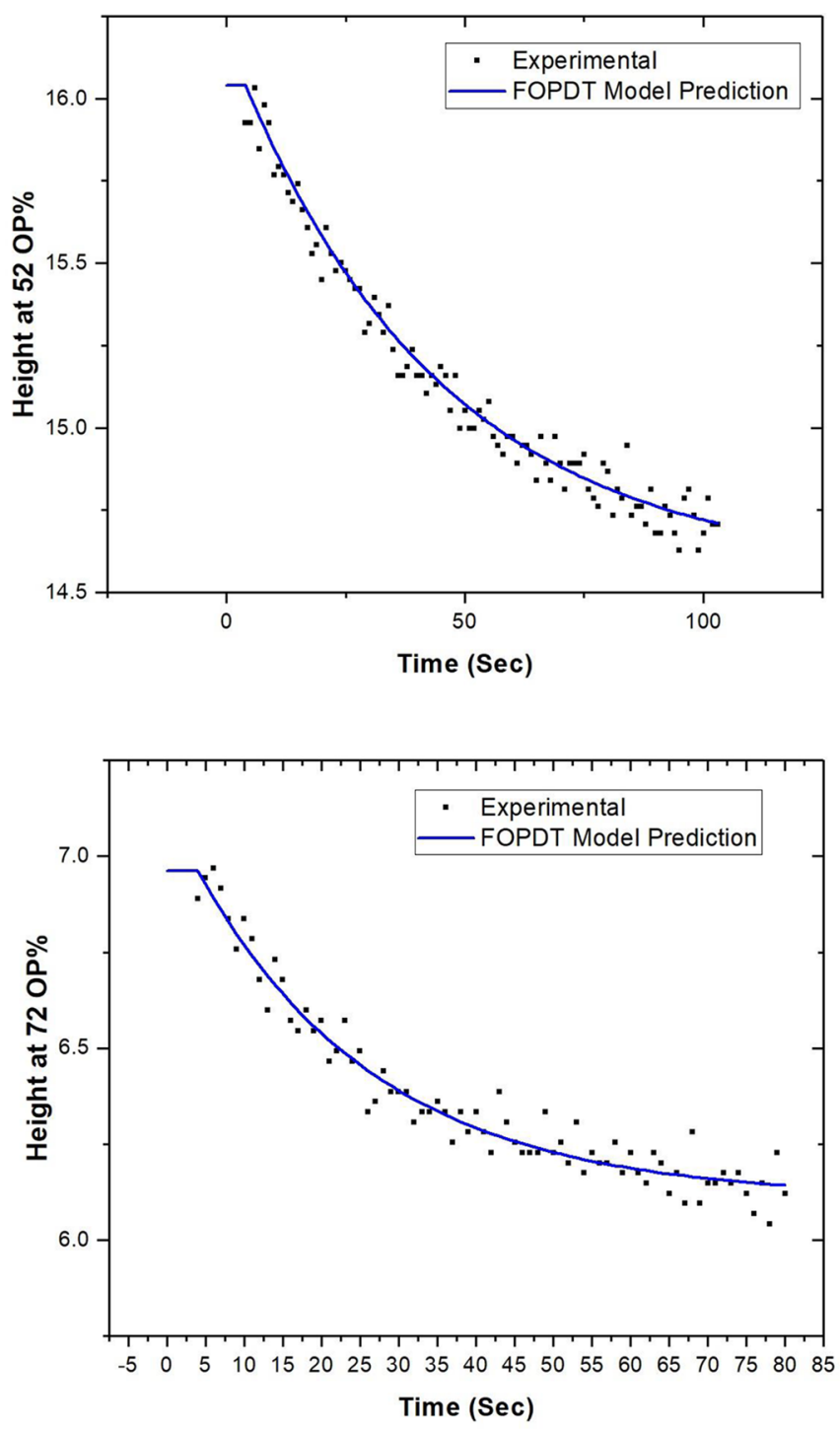

Figure 8. Comparison of FOPDT Model predictions with the experimental data at different steady-states. 


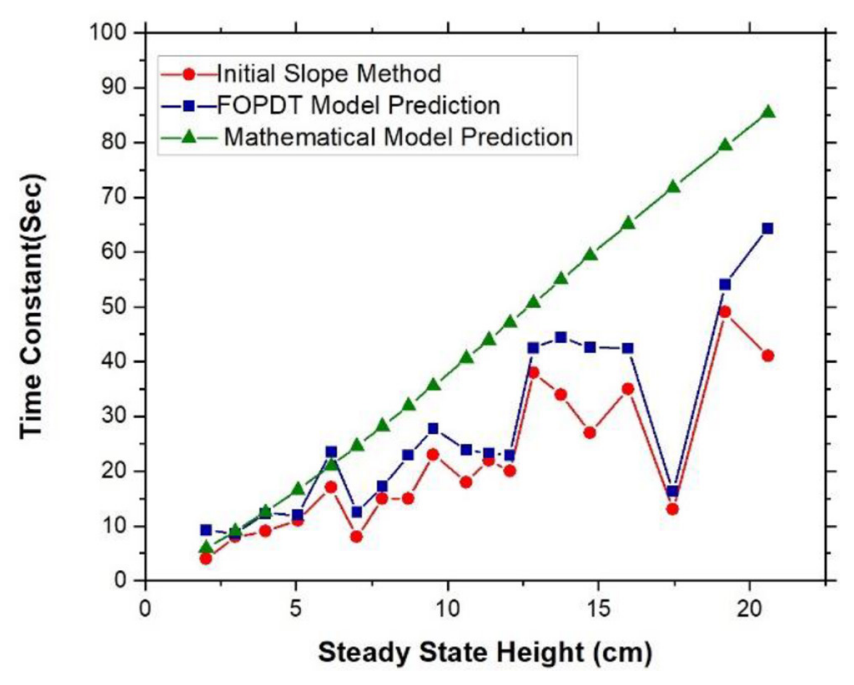

Figure 9. Variable time constant process.

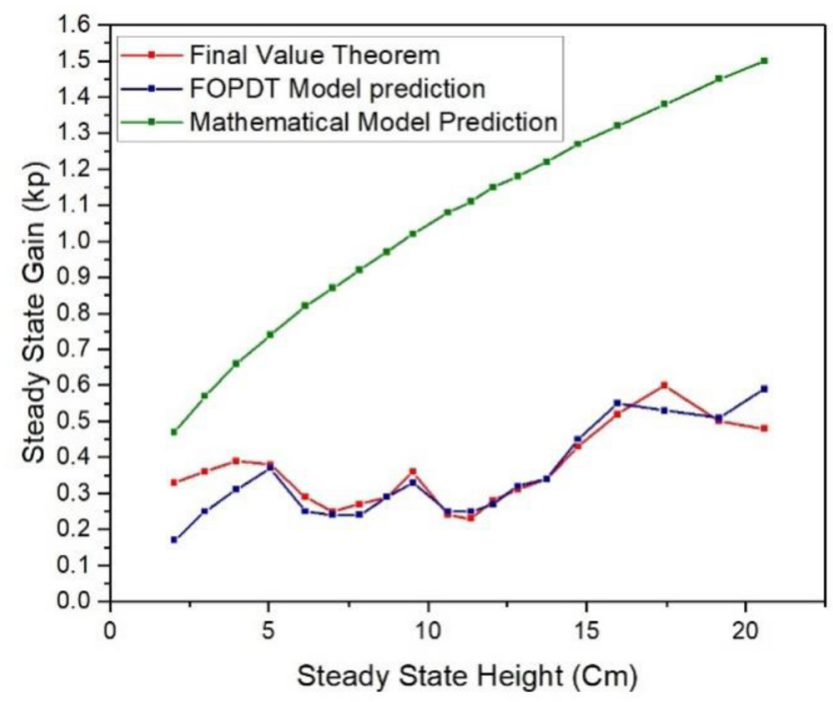

Figure 10. Variable gain process.

$$
\begin{gathered}
K c=\frac{0.67}{K}\left(\frac{\tau}{\theta}+0.185\right) \ldots \\
\tau_{I}=2.5 \theta\left(\frac{\tau+0.185 \theta}{\tau+0.611 \theta}\right) \ldots \\
\tau_{D}=0.37 \theta\left(\frac{\tau}{\tau+0.185 \theta}\right) \cdots
\end{gathered}
$$

where, $\mathrm{K}_{\mathrm{C}}, \tau_{1}$ and $\tau_{D}$ represent the controller parameters and $K, \tau$ and $\theta$ represent the gain, time constant and dead time of the process transfer function. The PID controller was tuned at four different steady-state heights namely $6.15 \mathrm{~cm}, 10.62 \mathrm{~cm}, 14.71 \mathrm{~cm}$ and $20.59 \mathrm{~cm}$ cor- responding to $25 \%, 43 \%, 60 \%$ and $84 \%$ respectively of the total tank height, as shown in Table 3. The transfer function parameters were taken from the FOPDT model identified earlier.In order to study the servo problem, the setup was operated in Auto mode. The closed loop performance of PID controller was studied at four different steady-states, in terms of quantitative performance indices such as ISE, IAE, ITAE, rise time, settling time and percentage overshoot. Table 4 shows the comparison of controller performance for servo problem, when the process was subjected to step changes in set point. Since the controller was tuned based on a fixed gain and time constant at a specific steady-state operating point, the PID controller performance was not satisfactory for significant step changes in setpoint.

\subsection{Tuning of IMC PID based Controller}

An IMC based PID controller has been designed to overcome the limitations of conventional PID controller. Figure 11 shows the closed loop block diagram of an IMC PID control system.

The parameters of IMC PID controller can be obtained based on the following equations:

$$
\begin{gathered}
K c=\frac{1}{K}\left(\frac{\tau+0.5 \times \theta}{\tau_{c}+0.5 \times \theta}\right) \cdots \\
\tau_{I}=\tau+0.5 \times \theta \ldots \\
\tau_{D}=\frac{\tau \times \theta}{2 \times \tau+\theta} \ldots
\end{gathered}
$$

where, the parameter $\tau_{C}$ has been set to the minimum possible value which is equal to the process time constant corresponding to the specified steady-state. The closed loop transfer function of an IMC PID based controller for servo problem is shown below:

$$
\begin{aligned}
G_{s p}(s)= & \frac{y(s)}{y_{s p}(s)}=\frac{G_{C}(s) G_{P}(s)}{1+G_{C}(s) G_{P}(s)}= \\
& \frac{\left(\frac{1}{\left(\tau+\frac{\theta}{2}\right)}+\frac{\tau \theta s}{2 \tau+\theta}+1\right) e^{-\theta s}}{\left(\frac{1}{\left(\tau+\frac{\theta}{2}\right)}+\frac{\tau \theta s}{2 \tau+\theta}+1\right) e^{-\theta s}+(\tau s+1)} \ldots
\end{aligned}
$$


Table 3. PID Controller tuning based on Cohen and Coon settings

\begin{tabular}{|l|l|l|l|l|}
\hline Steady State Height $(\mathrm{cm})$ & Transfer Function & Cohen Coon Setting & \multicolumn{2}{l|}{} \\
\cline { 3 - 5 } & & $K c=\frac{0.67}{K}\left(\frac{\tau}{\theta}+0.185\right)$ & $\tau_{I}=2.5 \theta\left(\frac{\tau+0.185 \theta}{\tau+0.611 \theta}\right)$ & $\tau_{D}=0.37 \theta\left(\frac{\tau}{\tau+0.185 \theta}\right)$ \\
\hline 6.15 & $\frac{0.25}{23.48 s+1} e^{-5 s}$ & 13.08 & 11.5 & 1.78 \\
\hline 10.62 & $\frac{0.25}{23.93 s+1} e^{-5 s}$ & 13.32 & 11.51 & 1.78 \\
\hline 14.71 & $\frac{0.45}{42.63 s+1} e^{-5 s}$ & 12.96 & 11.91 & 1.81 \\
\hline 20.59 & $\frac{0.51}{64.27 s+1} e^{-5 s}$ & 17.12 & 12.10 & 1.82 \\
\hline
\end{tabular}

Table 4. PID Controller closed loop performance indices at four different steady states

\begin{tabular}{|c|c|c|c|c|c|c|c|}
\hline \multicolumn{2}{|c|}{ Performance Indices } & ISE & IAE & ITAE & Overshoot \% & Rise Time (Sec) & Settling Time (Sec) \\
\hline \multirow{4}{*}{$\begin{array}{l}\text { Tuned at } \\
6.15 \mathrm{~cm}\end{array}$} & Tested at $6.15 \mathrm{~cm}$ & 169.21 & 473.09 & 3802.38 & 81.56 & 9 & 62 \\
\hline & Tested at $10.62 \mathrm{~cm}$ & 550.57 & 734.53 & 6499.44 & 80.48 & 9 & 55 \\
\hline & Tested at $14.71 \mathrm{~cm}$ & 613.01 & 796.31 & 7594.3 & 93.98 & 9 & 45 \\
\hline & Tested at $20.59 \mathrm{~cm}$ & 654.45 & 887.93 & 8348.50 & 80.89 & 9 & 35 \\
\hline \multirow{4}{*}{$\begin{array}{l}\text { Tuned at } \\
10.62 \mathrm{~cm}\end{array}$} & Tested at $10.62 \mathrm{~cm}$ & 169.21 & 473.09 & 3802.38 & 32.82 & 9 & 34 \\
\hline & Tested at $6.15 \mathrm{~cm}$ & 361.60 & 461.73 & 3600.37 & 81.86 & 9 & 40 \\
\hline & Tested at $14.71 \mathrm{~cm}$ & 345.46 & 456.92 & 3540.467 & 60.30 & 10 & 50 \\
\hline & Tested at $20.59 \mathrm{~cm}$ & 361.60 & 461.73 & 3600.37 & 81.86 & 9 & 40 \\
\hline \multirow{4}{*}{$\begin{array}{l}\text { Tuned at } \\
14.71 \mathrm{~cm}\end{array}$} & Tested at $14.71 \mathrm{~cm}$ & 169.21 & 473.09 & 3802.38 & 78 & 9 & 61 \\
\hline & Tested at $6.15 \mathrm{~cm}$ & 638.12 & 873.14 & 8125.71 & 77.59 & 9 & 66 \\
\hline & Tested at $10.62 \mathrm{~cm}$ & 732.64 & 1005.73 & 9397.98 & 77.05 & 9 & 71 \\
\hline & Tested at $20.59 \mathrm{~cm}$ & 593.74 & 776.22 & 7211.60 & 90.35 & 9 & 37 \\
\hline \multirow{4}{*}{$\begin{array}{l}\text { Tuned at } \\
20.59 \mathrm{~cm}\end{array}$} & Tested at $20.59 \mathrm{~cm}$ & 182.6327 & 631.46 & 5570.29 & 94.51 & 8.5 & 45 \\
\hline & Tested at $6.15 \mathrm{~cm}$ & 1597.99 & 2499.50 & 46431.98 & 96.77 & 8 & 114 \\
\hline & Tested at $10.62 \mathrm{~cm}$ & 1597.99 & 2499.59 & 46430.58 & 96.77 & 8 & 102 \\
\hline & Tested at $14.71 \mathrm{~cm}$ & 1857.39 & 2818.19 & 57305.84 & 109.8 & 10 & 109 \\
\hline
\end{tabular}

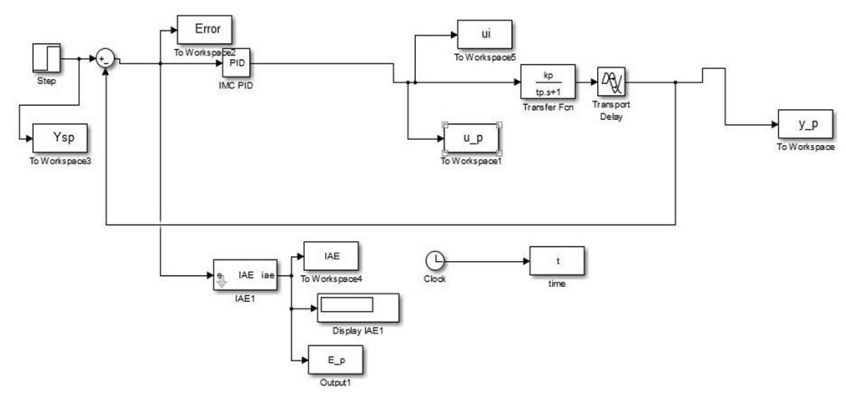

Figure 11. Closed loop block diagram of IMC PID controller.
Corresponding to the four steady-states described in the section above, the tuning parameters of IMC PID controller and the closed loop transfer functions have been shown in Tables 5 and 6 respectively.

\section{Experimental Validation of Closed Loop Response}

In order to compare the performance of IMC PID and conventional PID controllers, the physical setup was 
Table 5. Tuning parameters of IMC PID controller

\begin{tabular}{|l|l|l|l|l|}
\hline Steady State Height & Process Transfer Function & \multicolumn{2}{|l|}{ IMC PID controller tuning parameters } \\
\cline { 3 - 5 } & & $K c=\frac{1}{K}\left(\frac{\tau+0.5 \times \theta}{\tau_{c}+0.5 \times \theta}\right)$ & $\tau_{I}=\tau+0.5 \times \theta$ & $\tau_{D}=\frac{\tau \times \theta}{2 \times \tau+\theta}$ \\
\hline $6.15 \mathrm{~cm}$ & $\frac{0.25}{23.48 s+1} e^{-5 s}$ & 4 & 25.98 & 2.25 \\
\hline $10.62 \mathrm{~cm}$ & $\frac{0.25}{23.93 s+1} e^{-5 s}$ & 4 & 26.43 & 2.26 \\
\hline $14.71 \mathrm{~cm}$ & $\frac{0.45}{42.63 s+1} e^{-5 s}$ & 2.23 & 45.13 & 2.36 \\
\hline $20.59 \mathrm{~cm}$ & $\frac{0.51}{64.27 s+1} e^{-5 s}$ & 1.96 & 45.13 & 2.36 \\
\hline
\end{tabular}

Table 6. Close loop Transfer function using IMC PID

\begin{tabular}{|l|c|}
$\begin{array}{l}\text { Steady } \\
\text { Height }\end{array}$ & Close loop Transfer Function \\
using IMC-PID
\end{tabular}

Vol 12 (8) | Febraury 2019| www.indjst.org

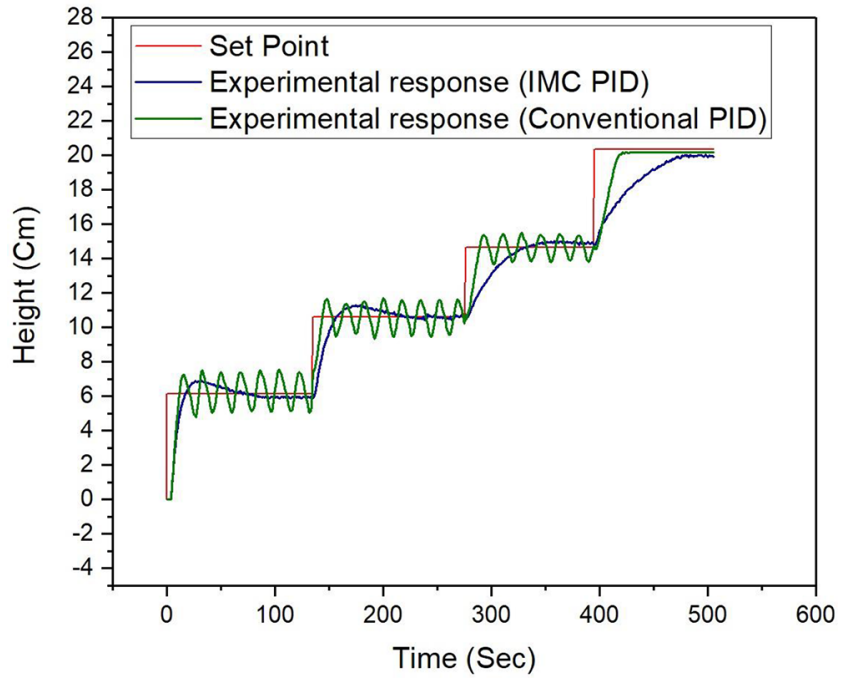

Figure12. Comparison of experimental closed loop responses of IMC PID and PID controller.

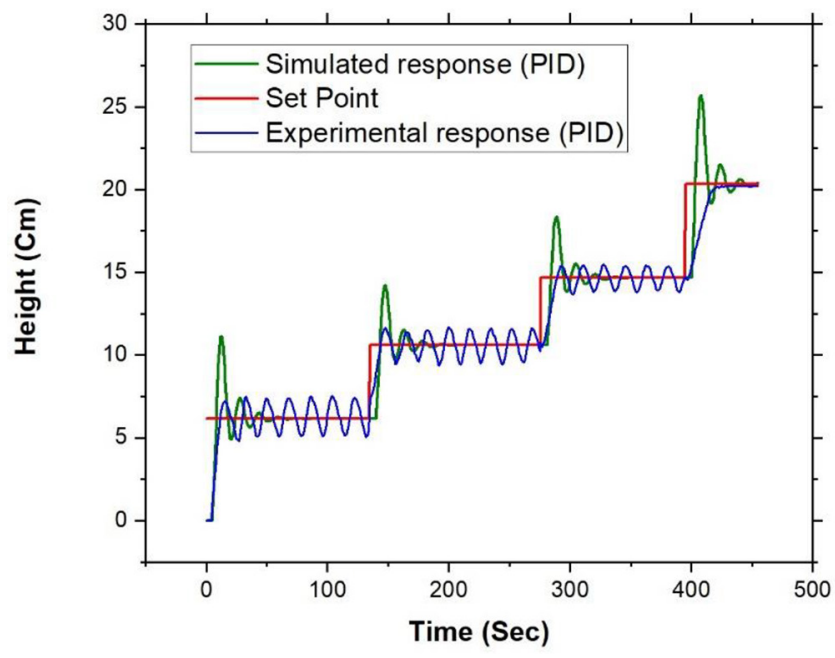

Figure 13. Comparison of simulated and experimental closed loop response of PID controller.

Indian Journal of Science and Technology | I I 


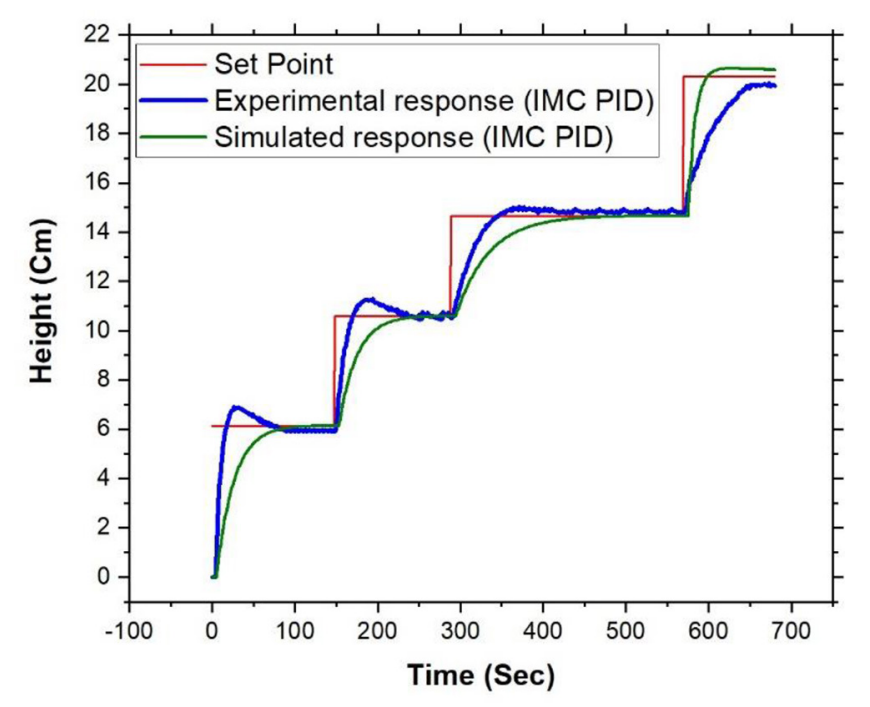

Figure 14. Comparison of simulated and experimental closed loop response of IMC PID controller.

operated in Auto mode by providing the controller parameters as obtained in Tables 5 and 6. Figure 12 show that the IMC PID controller provides more stabilized and superior performance.

In addition to experimental validation, the simulated closed loop responses of the IMC PID and the PID controllers were also obtained using the closed loop block diagram of Figure 11 and based on the FOPDT process transfer function. Figures 13 and 14 show the comparison of simulated and experimental results from the PID and IMC PID controllers respectively.

\section{Conclusion}

In this work, the dynamics and control of annular conical tank liquid level nonlinear process has been studied. Mathematical model of the process was developed and the process parameters were validated using the open loop experimental data obtained from the physical setup. The superior performance of IMC PID controller has been verified from both the closed loop simulations and experimental runs.

\section{References}

1. Article: Ziegler-Nichols' open loop method. http://techteach. no/publications/articles/zn_open_loop_method/zn_open_ loop_method.pdf. Date accessed: 17/07/2010.
2. Hägglund T, Åström KJ. Industrial adaptive controllers based on frequency response techniques. Automatica. 1991, 27 (4), pp. 599-609. https://doi.org/10.1016/00051098(91)90052-4

3. Tan KK, Ferdous R, Huang S. Closed-loop automatic tuning of PID controller for nonlinear systems. Chemical Engineering Science. 2002, 57 (15), pp. 3005-3011. https:// doi.org/10.1016/S0009-2509(02)00186-0

4. Madhuranthakam CR, Elkamel A, Budman H. Optimal tuning of PID controllers for FOPTD, SOPTD and SOPTD with lead processes. Chemical Engineering and Processing: Process Intensification. 2008, 47 (2), pp. 251-264. https:// doi.org/10.1016/j.cep.2006.11.013

5. Chakravarthi MK, Vinay PK, Venkatesan N. Design and simulation of internal model controller for a real time nonlinear process. Indian Journal of Science and Technology. 2015, 8 (19), pp. 1-6. https://doi.org/10.17485/ijst/2017/ v10i19/91682

6. Angeline D, Vivetha K, Gandhimathi K, Praveena T. Model based controller design for conical tank system. International Journal of computer application. 2014, 85 (12), pp. 8-11.

7. Yadav ES, Indiran T, Shankar N. Optimal Actuation of Controller using Predictive PI for Nonlinear Level Process. Indian Journal of Science and Technology. 2016, 9 (34), pp. 1-4.

8. Rivera DE, Morari M, Skogestad S. Internal model control: PID controller design. Industrial \& engineering chemistry process design and development. 1986, 25 (1), pp. 252-65. https://doi.org/10.1021/i200032a041

9. Parrish JR, Brosilow CB. Nonlinear inferential control. AIChE Journal. 1988, 34 (4), pp. 633-644. https://doi.org/ 10.1002/aic.690340413

10. Bhuvaneswari NS, Uma G, Rangaswamy TR. Adaptive and optimal control of a non-linear process using intelligent controllers. Applied soft computing. 2009, 9 (1), pp. 182-190. https://doi.org/10.1016/j.asoc.2008.04.003

11. Soft computing based controllers Implementation for non-linear process in real time. http://www.iaeng.org/ publication/WCECS2010/WCECS2010_pp1021-1025.pdf. Date accessed: 20/10/2010.

12. Tamilselvan GM, Aarthy P. Online tuning of fuzzy logic controller using Kalman algorithm for conical tank system. Journal of Applied Research and Technology. 2017, 15 (5), pp. 492-503. https://doi.org/10.1016/j.jart.2017.05.004

13. Srinivasan K, Sindhiya D, Devassy J. Design of fuzzy based model predictive controller for conical tank system. IEEE International Conference on Control and Robotics Engineering (ICCRE). 2016, pp. 1-6. https://doi. org/10.1109/ICCRE.2016.7476135

14. Ramanathan P, Mangla KK, Satpathy S. Smart controller for conical tank system using reinforcement learning algo- 
rithm. Measurement. 2018, 116, pp. 422-428. https://doi. org/10.1016/j.measurement.2017.11.007

15. Dinesh C, Manikanta VV, Rohini HS, Prabhu KR. Real time level control of conical tank and comparison of fuzzy and classical PID controller. Indian Journal of Science and Technology. 2015, 8(2), pp. 40-44. https://doi.org/10.17485/ ijst/2015/v8iS2/58407

16. Keerthana PG, Gnanasoundharam J. Comparison of PI controller, model reference adaptive controller and fuzzy logic controller for coupled tank system. Indian Journal of Science and Technology. 2016, 9 (12), pp. 1-5.

17. Betancor-Martín CS, Montiel-Nelson JA, Vega-Martínez A. Direct inverse control for a conical tank by using TakagiSugeno fuzzy model. International Journal of Advanced Research in Electrical, Electronics and Instrumentation Engineering. 2013, 2 (11), pp. 532-542.
18. Fruehauf PS, Chien IL, Lauritsen MD. Simplified IMCPID tuning rules. ISA Transactions. 1994, 33 (1), pp. 43-59. https://doi.org/10.1016/0019-0578(94)90035-3

19. Process Control Modelling, Design and Simulation. https://books.google.co.in/books/about/Process_Control. html?id=PdjHYm5e9d4C. Date accessed: 2003.

20. Process Dynamics Modelling, Analysis and Simulation. https://eleccompengineering.files.wordpress.com/2015/10/ process-dynamics_modeling_analysis_and_simulation_ wayne_bequette.pdf. Date accessed: 1998.

21. Tavakoli S, Tavakoli M. Optimal tuning of PID controllers for first order plus time delay models using dimensional analysis. International Conference on Control and Automation Proceedings; 2003. p. 942-6. https://doi.org/ 10.1109/ICCA.2003.1595161

22. Apex innovations [Internet]. [cited 2014]. Available from: http://www.apexinnovations.co.in/. 